\title{
Teoría de la Información y de la Comunicación en una serie de Televisión: Scandal
}

\author{
Graciela Padilla Castillo \\ Universidad Complutense de Madrid \\ gracielapadilla@ccinf.ucm.es
}

\begin{abstract}
Resumen:
Este trabajo analiza las crisis planteadas y resueltas por el personaje de Olivia Pope y sus trabajadores, en los 29 capítulos de las dos primeras temporadas de la serie de televisión Scandal. Cada uno de ellos está inspirado en crisis reales y suponen una brillante exposición de cómo comunicar e informar. Además, la serie aborda diferentes tipologías de crisis: personales, institucionales, empresariales, políticas, militares, sanitarias. Lejos de ser una ficción televisiva, puede erigirse como vehículo didáctico para aprender y enseñar a comunicar. Para demostrarlo, se expondrán las crisis y cómo se resuelven, aludiendo a teorías de la historia de la comunicación.
\end{abstract}

Palabras clave: Teoría de la Información; teoría de la comunicación; comunicación de crisis; Scandal; Shonda Rimes.

\section{Information Theory and Communication in a Television Series: Scandal}

\begin{abstract}
:
This paper analyzes the crises raised and resolved by the character of Olivia Pope and her workers in the 29 chapters of the first two seasons of the TV series Scandal. Each one is inspired by real crisis and is a brilliant exposition of how to communicate and inform. In addition, the TV series focuses on different types of crisis: personal, institutional, corporate, political, military, health. Far from being a television fiction, can be erected as a vehicle for learning and teaching to communicate. To prove it, we will present crises and how they are resolved, alluding to theories of the history of communication.
\end{abstract}

Key words: Information theory; communication theory; crisis communication; Scandal; Shonda Rimes.

\section{Referencia normalizada:}

Padilla Castillo, G. (2014): Teoría de la información y de la comunicación en una serie de televisión: Scandal. Historia y Comunicación Social. Vol. 19. Núm. Especial Febrero. Págs. 133-144.

Sumario: 1. Introducción; 2. Metodología; 3. Shonda Rhimes. La productora; 4. Judy Smith. La inspiración real; 5 . Análisis de contenido de los episodios; 6 . Conclusiones; 7. Referencias bibliográficas.

\section{Introducción}

Scandal es una serie de televisión de origen norteamericano, emitida por ABC (American Broadcasting Company) desde el 5 de abril de 2012. Hasta septiembre de 2013 , cuenta con dos temporadas de 7 y 22 capítulos, respectivamente. Ha tenido un notable éxito de audiencia, registrando entre 7 y 9 millones de espectadores en Estados Unidos. Asimismo, ha sido exportada a 33 países de todo el mundo. En España, es emitida por Fox y Cuatro desde el verano de 2013. 
Cada entrega dura 43 minutos y contiene una trama auto-conclusiva: la protagonista, Olivia Pope, y su equipo deben arreglar una crisis de comunicación de algún cliente. Dicha crisis abre cada capítulo y se resuelve al final del mismo. Aparte de esas tramas episódicas, con personajes también episódicos, hay tramas largas para cada temporada, que afectan a los protagonistas y a la empatía que pueden provocar en los espectadores. Sin embargo, sólo nos centraremos en las tramas auto-conclusivas por su importancia para la didáctica de comunicación e información.

Los artífices son un equipo variado de guionistas y directores; personas de gran confianza para Rhimes porque han trabajado con ella en sus series precedentes o en otras de similar éxito. Otra de las parcelas más vigiladas es la música. Scandal cuenta con partituras propias, creadas por Chad Fischer, y temas de artistas ajenos a la serie. Anatomía de Grey (Grey's Anatomy) y Sin cita previa (Private Practice) destacaron, previamente, por la cuidada elección de temas musicales. Shonda Rhimes delegó este trabajo en Alexandra Patsavas y ha vuelto a confiar en ella en Scandal. Para conocer la figura de Patsavas y descubrir una relación muy interesante entre las series de televisión y la música, recomendamos la lectura de Padilla y Requeijo (2011).

Volviendo a la producción, podemos añadir que Scandal se rueda en Los Ángeles (California), aunque la ficción se desarrolla en Washington, D.C., siempre en torno a la Casa Blanca. La producen ShondaLand, productora de Shonda Rhimes, y ABC Studios.

\section{Metodología}

Tras haber presentado los principales datos de producción de la serie, abordaremos una búsqueda bibliográfica completa para conocer a Shonda Rhimes, productora de la serie, y a Judy Smith, socia de Rhimes en Scandal, guionista y persona real que inspiró el producto final. Asimismo, se procederá al análisis de contenido de los 29 capítulos emitidos, como elementos didácticos de teoría de la comunicación y de la información. Para ello, se han empleado tres manuales imprescindibles: La investigación de la comunicación de masas, Crítica y perspectiva (Mauro Wolf, 1987), Teoría General de la Información (Felicísimo Valbuena, 1997) y Teoría de la Información y la Comunicación efectiva (Eva Aladro, 1999).

\section{Shonda Rhimes. La productora}

Para conocerla en profundidad, recomendamos algunas lecturas académicas: Padilla (2010), Padilla y Requeijo (2010), Padilla y Requeijo (2011) o Martínez de Albéniz y Moreno del Río (2013). Rhimes nació en Chicago, en 1970, en una familia de cinco hermanos y progenitores del ámbito universitario: su madre era profesora y su padre, gerente de la Universidad de Chicago. Se licenció en la Universidad de Dartmouth y 
consiguió una beca para un máster de guión en cine y televisión, en la Universidad de Southern California. Al terminar, estuvo en paro varios meses. La excepción fueron el documental Hank Aaron: Chasing the Dream (1995) y el cortometraje Blossoms and Veils (1998), adquirido por New Line Cinema. Poco después, llegó su oportunidad como guionista de la TV movie Dorothy Dandridge, en 1999, que dio la fama a la actriz Halle Berry. Y de ahí al cine para adolescentes con dos títulos: Crossroads: hasta el final (interpretada por la cantante Britney Spears), en 2002, y Princesa por sorpresa 2 (The Princess Diaries 2: Royal Engagement), en 2004.

El 27 de marzo de 2005 se emitía el primer capítulo de Anatomía de Grey y su currículum cambiaría para siempre. La serie, llamada a ser un producto de transición de media temporada, convenció a la audiencia. Pasó de la parrilla del domingo a la del jueves, día estelar del prime time norteamericano. Reavivó las series médicas, junto a House (House, M.D.), que no disfrutaban de tal esplendor desde Urgencias $(E R)$. Y convirtió a Shonda Rhimes en una de las 100 personas más influyentes del mundo, según el ranking de la revista Time.

El éxito de la serie llevaría a la aparición de una secuela o spin off. La doctora Addison Montgomery salió de Anatomía de Grey para tener su propio show. En la ficción, se marchaba de Seattle a Los Ángeles. En la realidad, el entonces marido de la actriz, ejecutivo de la $\mathrm{ABC}$, propuso a Shonda Rhimes que crease una nueva serie completa, como había elaborado Anatomía de Grey. Se hizo para el lucimiento de la actriz Kate Walsh y Rhimes quedó contenta porque también la producía con su empresa, ShondaLand. El público confió en el producto, durante 6 temporadas y 111 episodios, entre 2007 y 2013 (Padilla, 2010: 202).

En definitiva, con dos series corales, de Seattle a Los Ángeles, de la medicina más tecnológica a la más naturista, de médicos jóvenes a otros experimentados que huyen de la gran ciudad, Shonda Rhimes cimentó su área intocable. Su fama, poder y dinero crearon el momento propicio para materializar una idea que surgió en 2009, cuando conoció a Judy Smith y desarrollaron Scandal.

\section{Judy Smith. La inspiración real}

La otra mitad de Scandal es Judy Smith. Fue jefa de prensa del ex presidente George H.W. Bush. Desarrolló su tarea en varios momentos históricos, importantes desde la comunicación y la información: la Guerra del Golfo de 1991 y las relaciones con Irán y Kuwait. Después de abandonar la Casa Blanca, creó la agencia Smith \& Company, especializada en resolución de crisis y base real para crear la empresa ficticia Olivia Pope and Associates, centro de la serie de televisión.

Nació en 1958, en Washington, D.C. Estudió Relaciones Públicas en la Universidad de Boston y al acabar sus estudios, fue ayudante de comunicación del Colegio de Obstetras y Ginecólogos de su ciudad natal. Poco después, en 1989, se convirtió 
en adjunta del portavoz del fiscal del Distrito de Columbia. Curiosamente, este cargo tendría gran importancia, años después, en la serie Scandal, donde aparece el mismo personaje: David Rosen, interpretado por el actor Joshua Malina.

Estuvo en ese cargo dos años porque en 1991, pasó a formar parte del gabinete del presidente de Estados Unidos, George H.W. Bush. El cuadragésimo primer mandatario del país ocuparía su cargo entre 1989 y 1993. Antes, había sido vicepresidente de Ronald Reagan, entre 1981 y 1989, y director de la Agencia Central de Inteligencia (CIA), entre 1975 y 1977. No es casualidad que la CIA también sea parte imprescindible de la trama de Scandal.

En el gobierno de Bush, la política internacional fue una parte fundamental. Invadió Panamá el 20 de diciembre de 1989, en la Operación Causa Justa, para capturar al general Manuel Antonio Noriega, líder castrense y entonces dictador del país. Inició la Guerra del Golfo en el verano de 1990, con una coalición de 31 países y la autorización de Naciones Unidas, como respuesta a la invasión de Kuwait por parte del entonces líder iraquí Saddam Hussein. El conflicto duró hasta febrero de 1991. Y en junio de 1993, el presidente ordenó bombardear de nuevo Irak, en represalia contra la supuesta conspiración que pretendía acabar con su vida. De nuevo, la realidad invadiría la ficción porque el presidente Fitzgerald Grant, en Scandal, interpretado por Tony Goldwyn, vive la misma amenaza.

Tras acabar la legislatura y abandonar la Casa Blanca, Judy Smith fundó su empresa: Smith \& Company, especializada en gestión de crisis. Ha trabajado en la I Guerra del Golfo, el caso Lewinsky, los disturbios de Los Ángeles, el nombramiento del juez de la Corte Suprema, Clarence Thomas, la investigación del Congreso estadounidense sobre el caso Enron, la respuesta de la Organización Mundial de la Salud (OMS) a la epidemia de SARS (Síndrome Respiratorio Agudo Severo, en castellano), además de asesorar a varias agencias y organismos gubernamentales de su país y de otras administraciones extranjeras, como Filipinas, Haití, Jamaica, Turquía y Zimbabue. Smith también fue vicepresidenta del gabinete de comunicación de la cadena de televisión norteamericana NBC (National Broadcasting Company). Y gracias a este trabajo, en 2009, le presentaron a Shonda Rhimes y a su socia, Betsy Beers. El encuentro se había programado para durar alrededor de media hora. Pero las tres mujeres conversaron durante varias horas y nació el germen de Scandal. Judy Smith se convertiría en productora ejecutiva de la serie, junto a Rhimes, y por supuesto, asesora de la trama y del guión.

\section{Análisis de contenido de los episodios}

En las líneas siguientes, se presentarán los capítulos de las dos primeras temporadas de Scandal, con la crisis de comunicación que plantean, su resolución y la teoría de información y comunicación a la que remite y de la que podría ser ejemplo didáctico en las aulas universitarias. 
Temporada 1. Episodio 1: Bomboncito (Sweet baby): Un teniente militar, héroe de guerra, republicano, contrario al aborto y a los homosexuales, acude a la oficina de Olivia Pope antes de que la policía le detenga por asesinar a su novia. Es inocente, pero teme defenderse con una prueba que mostraría su verdadera vida: es gay, tiene novio e iba a casarse con la chica porque es su mejor amiga y ambos habían decidido construir esa tapadera de cara a los medios de comunicación. El cliente quiere optar por la reserva, tal como la definió Ray Eldon Hiebert (Valbuena, 1997: 246-248). Olivia quiere que diga la verdad, no vaya a la cárcel y confiese su homosexualidad, en rueda de prensa o publicación.

Episodio 2: Trapos sucios (Dirty little secrets): La propietaria de un negocio de prostitución está siendo investigada por la policía y acude a Olivia Pope and Associates para que su cartera de clientes siga en la sombra. David Rosen, ayudante del fiscal del distrito, se enfada con la protagonista porque sabe que sus empleados han cogido todas las pruebas justo antes del registro policial. Entre esas pruebas, hay una larga lista de clientes que ocupan altos cargos políticos y empresariales. La lista es un ejemplo acertadísimo de reserva, tal como lo definió Hiebert. Debe seguir siendo secreto oficial por el bien político del país.

Episodio 3: No hay furia en el infierno (Hell hath no fury): Travis, el hijo de un matrimonio millonario, es acusado de violación. Olivia Pope y su equipo manejan la crisis y consiguen que sea absuelto. Sin embargo, descubren que es culpable y que violó a otra chica en el pasado. Su madre decide que le detenga la policía, por ese delito antiguo, y porque no le ve capaz de continuar el negocio familiar. Cree que necesita ser castigado. El posible escarnio público es mejor que vivir con esa falta en la conciencia. Según la tipología de acontecimientos públicos, de Harvey Molotch y Marilyn Lester, nos encontramos ante un escándalo controlado por la progenitora.

Episodio 4: Enemigo del Estado (Enemy of the State): Un dictador latinoamericano, Benicio Flórez, acude a Olivia para que encuentre a su mujer y a sus hijos, que presuntamente han sido secuestrados. Es enemigo declarado de Estados Unidos y cree que los culpables son agentes del FBI. La realidad es que su mujer ha huido, quiere divorciarse de él y quedarse con los niños; aunque la legislación de su país dicte lo contrario. Olivia le convence de que acceda al divorcio y deje a los pequeños con su madre, después de plantearle un dilema: ella sigue siendo la madre de sus hijos o se convierte en su principal oposición política y acaba con su poder. Flórez opta por quitar toda la noticiabilidad (newsworthiness) a su divorcio, tal como lo definió Garbarino (Wolf, 1996: 215), para que no se convierta en escándalo.

Episodio 5: Accidente mortal (Crash and burn): El piloto de un avión comercial contrata a Olivia Pope para defenderse de los medios de comunicación y demostrar que no ha sido culpable del accidente en el que han fallecido varios pasajeros. Escuchando la grabación de la caja negra, deducen que el fallo fue culpa de la aerolínea: un informe desaparecido avisaba de problemas técnicos aunque una empleada no pudo atenderlo por falta de tiempo. El propietario de la aerolínea pide disculpas 
públicamente (publicación y puesta en escena), siguiendo el consejo de Olivia, y consigue que su compañía siga existiendo a pesar del accidente.

Episodio 6: El rastro (The trail): Este capítulo se remonta a la carrera electoral hacia la Casa Blanca. El entonces gobernador Fitzgerald Grant pierde las elecciones en New Hampshire porque el equipo de su contrincante, Sally Langston, revela una supuesta relación extramatrimonial de la señora Grant. Ésta da un vuelco a las encuestas diciendo a los medios que perdió un bebé y que aún no han superado esa pérdida. Cuando abraza a su marido, ante las cámaras, le reconoce en voz baja, que se lo ha inventado para llegar al corazón de los votantes y eliminar los rumores de su infidelidad. El equipo de Langston ha empleado la opposition research o investigación del contrario (Valbuena, 1997) para buscar los trapos sucios. Y Mellie, Grant, el efecto de recencia, dando la noticia del aborto justo al final de una rueda de prensa, con publicación y puesta en escena.

Episodio 7: Grant para el pueblo (Grant: For the people): Quinn Perkins, empleada de Olivia, encuentra muerto a su novio, Gideon Wallace, periodista de investigación obsesionado con desvelar un escándalo del presidente Grant. No pueden llamar a la policía porque sabrían quién es Quinn en realidad. Y deciden limpiar la escena del crimen, como si nada hubiera ocurrido (reserva). Ella decide entregarse al fiscal David Rosen para lavarr su imagen y un turbio asunto del pasado (escándalo controlado), aún desconocido por los espectadores.

Temporada 2. Episodio 1: Quinn es Quinn Perkins (White hats off): Un congresista de Rhode Island pide ayuda a Olivia porque ha encontrado cámaras y micrófonos en su despacho. Confiesa que ha tenido relaciones sexuales con una amiga sobre el escritorio y el partido de la oposición amenaza con lanzar por Internet sus vídeos (opposition research). Olivia decide utilizar a la prensa, concentrada en el congresista, para hablar de sus propuestas de reforma educativa y da un giro al asunto (neutralización de la información negativa y cambio de los temas de la agenda de los medios). Ha conseguido la visibilidad mediática que necesitaba y con su oratoria, ha enterrado los vídeos que son olvidados y obviados por ser parte de su vida privada.

Episodio 2: La otra mujer (The other woman): Un reverendo fallece practicando sexo con una prostituta. Olivia Pope traslada el cadáver a la casa de su cliente y pide a la mujer que firme un contrato de confidencialidad (reserva). Le tumban en su cama, con su pijama, para que su esposa denuncie la muerte, como si hubiera ocurrido de forma natural, en el hogar (puesta en escena). La prostituta rechaza el contrato y el dinero porque en realidad, es la amante del reverendo y tiene un hijo de él. Sólo quiere asistir al funeral o contárselo todo a los medios de comunicación (publicación sobre un accidente). Olivia convence a la viuda de que acceda, para que la memoria de su marido quede impoluta, y las dos mujeres se apoyan al salir de la iglesia.

Episodio 3: Temporada de caza (Hunting Seaton): Arthur, un informático que trabaja para el gobierno, acude a la oficina de Olivia Pope porque dice que le quieren matar. Manifiesta haber encontrado un programa que vigila a todos los norteamericanos. En realidad, lo ha robado y quiere venderlo al mejor postor, engañando al 
equipo entero de Olivia Pope. Ésta se da cuenta del engaño a tiempo y le entrega a las autoridades (reserva).

Episodio 4: Cinturón desabrochado (Beltway unbuckled): Un matrimonio tradicional y religioso pide ayuda a la protagonista porque su hija, Jennifer, ha desaparecido y la policía no da prioridad al caso. En realidad, resulta ser una bloguera famosa, que mantiene sexo con muchos políticos y escribe sobre sus experiencias en la red. Encuentran su cadáver; le ha matado un diplomático de Kurdistán y como tiene inmunidad diplomática, no va a la cárcel. Olivia consigue que la mujer del presidente, Mellie Grant, apoye a los padres en público, en la explanada de césped frente a la Casa Blanca (puesta en escena). Dice que va como madre, no como primera dama. Y se olvidan de lo que hacía Jennifer para que quede como inocente víctima y concentren a la población en pedir una nueva legislación contra esa inmunidad diplomática (neutralización de la información negativa).

Episodio 5: Todos los caminos llevan a Fitz (All roads lead to Fitz): El gobernador de Maryland, Samuel Reston, llama a Olivia Pope porque ha matado al hombre que, supuestamente, violaba a su mujer. Era el obrero que les estaba haciendo la reforma de su casa desde hacía meses. David Rosen acusa al gobernador de homicidio, porque su mujer llevaba varios meses de relación con el hombre fallecido. Ella decide contar la verdad, entregarse a la policía y limpiar el nombre de su esposo (publicación y newsmaking o fabricación de la noticia para que sólo afecte a la mujer).

Episodio 6: Espía como nosotros (Spies like us): Olivia recibe por correo postal una partitura de música y un cheque de 100.000 dólares. Contiene una lista de nombres de espías norteamericanos; entre ellos, Huck, ahora empleado de Olivia. Algunos de esos espías se están suicidando en público antes de ser asesinados. Huck reúne a todos los integrantes de la lista en el despacho de Olivia y descubre que uno de ellos ha vendido los nombres a cambio de una importante transferencia en una cuenta bancaria de Suiza. Huck quiere perdonarle pero otra de las espías presentes le mata y entre todos, limpian el escenario (reserva).

Episodio 7: Desafio (Defiance): Un millonario, Harold Pierce, se divorcia de su mujer, deja su negocio familiar boyante, y se casa con su joven novia, tres días antes de que su empresa salga a Bolsa (escándalo). La familia quiere que se acalle la situación y salgan las acciones sin que se sepa nada (reserva). En realidad, Harold quiere parecer senil, acabar con el negocio y que su hijo no esté atado al dinero, como lo ha estado él toda la vida. Sin embargo, llegan a un acuerdo porque el primogénito no quiere el dinero; de verdad cree en el negocio familiar y éste es su vida.

Episodio 8: Feliz cumpleaños, señor presidente (Happy Birthday, Mr. President): El presidente Fitzgerald Grant ha sido víctima de un intento de asesinato y mientras lucha por su vida en el hospital, Olivia decide volver a su equipo como portavoz (puesta en escena). Para callar los rumores, convence a Mellie Grant de que hable ante los medios, diga que su marido aún está vivo y que sus ciudadanos no deben abandonarle (puesta en escena, publicación y persuasión, tal como las definió Hiebert). 
Episodio 9: Volar por los aires (Blown away): Huck es víctima de una trampa: su novia, Becky Flynn, es en realidad una espía y quiere implicarle como culpable del intento de asesinato del presidente Grant. Las autoridades tienen esas pruebas falsas, pero no quieren que se filtren a los medios de comunicación (reserva). Mientras, Olivia reúne un comité para organizar el posible funeral de Estado del presidente, que continúa en estado crítico (puesta en escena).

Episodio 10: Uno para el perro (One for the dog): Mellie Grant decide lanzar una noticia falsa: anunciar que su marido ha despertado súbitamente del coma (globo sonda). Además, ha falsificado su firma para evitar las acciones militares y las reformas que está planeando, en su lugar, la vicepresidenta Sally Langston. Como no la soportan, resuelven mantener la mentira, esconder al presidente y gobernar por él, como si estuviera vivo (mentira necesaria para evitar el caos político).

Episodio 11: Un criminal, una puta, un idiota y un mentiroso (A criminal, a whore, an idiot and a liar): El presidente Grant decide volver al trabajo rápidamente, aunque su cirujana le ha dicho que debe guardar reposo. Él prefiere correr el riesgo antes de que la vicepresidenta tome decisiones con las que no está de acuerdo. Además, dice que el pueblo necesita verle y saber que está ahí (puesta en escena). Al mismo tiempo, en flashbacks, aparece un momento crucial de la carrera electoral, donde su padre, también político, le recomienda que busque un asunto turbio de su contrincante, el gobernador Samuel Reston, porque es la única manera de vencerle (opposition research).

Episodio 12: La verdad y sus consecuencias (Truth or consequences): El fiscal David Rosen tiene pruebas de que el magnate y empresario Hollis Doyle ordenó matar al presidente y años antes, falsificó las máquinas de voto electoral para hacerle llegar a la Casa Blanca (escándalo). Como hay mucho dinero en juego, la abogada de Doyle convence al fiscal de que le deje libre porque nadie se va a creer la conspiración y Rosen sólo va a hacer el ridículo (reserva y neutralización de la información negativa).

Episodio 13: A nadie le gustan los bebés (Nobody likes babies): Mellie Grant se niega a concederle el divorcio a su marido, el presidente Fitzgerald Grant. Le amenaza con arruinar su carrera política y acabar ocupando sola la Casa Blanca. Poco después, la jueza del Tribunal Supremo, Verna Thornton, le confiesa al mandatario, en su lecho de muerte, que ganó las elecciones porque ella y su equipo, incluida Olivia Pope, manipularon las máquinas de votar. Fitzgerald le quita la mascarilla de oxígeno y acelera su muerte antes de que pueda confesarlo ante un juez (reserva).

Episodio 14: Whiskey Tango Foxtrot: El ex fiscal David Rosen se levanta con un cuchillo en su mano, al lado de una mujer asesinada, Wendy, y manchado de la sangre de ella. Llama a Olivia Pope para que le ayude y su equipo traslada el cadáver a la casa de la chica, para que la policía encuentre allí el cuerpo (puesta en escena). El caso se silencia porque Wendy tenía información confidencial sobre la seguridad del país (reserva) y estaba copiando archivos del ordenador de Rosen, la misma noche en que murió. 
Episodio 15: Bum, hace la dinamita (Boom goes the dynamite): El senador por el estado de Indiana quiere que su hermano menor, el congresista Will Caldwell, deje de ser soltero porque los votantes creen que es homosexual y así no podrá ser gobernador. Saben que el pueblo no quiere a nadie a quien no pueda encasillar, porque no se fiaría de él. En realidad, Will está enamorado de su cuñada, con la que mantiene una relación desde hace años. Accede a casarse, con una joven que Olivia Pope ha seleccionado, perfecta para la opinión pública (puesta en escena). Su hermano decide olvidar la relación que mantenía con su mujer, por el bien y la imagen de la familia.

Episodio 16: Hora de inicio (Top of the hour): Sarah Stanner, una importante y exitosa directiva, es acusada de mantener una relación extramatrimonial con el juez Murray Randall, que está a punto de ser ascendido al Tribunal Supremo (escándalo). Ella da una rueda de prensa y explica que sólo tuvieron un encuentro amoroso, hace 15 años, cuando los dos estaban ya casados, y eran alumna y profesor en la Universidad de Harvard (publicación y puesta en escena). Horas después, se desvela que estuvieron juntos varios años y el marido de Sarah pide una prueba de paternidad porque cree que su hija es del juez. Asimismo, la junta directiva de Ryo Corp, la empresa donde trabaja Sarah, quiere despedirla por incumplir su cláusula ética (puesta en escena). Harrison y Abby, empleados de Olivia Pope, amenazan a los directivos con sacar todos sus trapos sucios, como se han publicado los de Sarah. Retiran la demanda, readmiten a la directiva y los periodistas se olvidan del asunto cuando Sarah vuelve a ser feliz con su familia (neutralización de la información negativa).

Episodio 17: Serpiente en el jardin (Snake in the garden): El magnate del petróleo, Hollis Doyle, contrata a Olivia Pope cuando recibe un vídeo de su hija, en el que dice que la tienen secuestrada y piden 20 millones de dólares por su vida. Al examinar la oreja que, supuestamente, le cortaron como prueba de vida, Huck descubre que el secuestro ha sido una farsa. Sus padres quieren entregarla a la policía por inventar esa gran mentira. Y Doyle accede a darle el dinero que pide, a cambio de que desaparezca para siempre de sus vidas (reserva). Ella elige el dinero, en lugar de su familia y no aparece en los medios.

Episodio 18: Molly, estás en peligro, chica (Molly, you in danger, girl): Susan Osborne, la viuda de Grayden Osborne, jefe del FBI acusado de alta traición, acude a la oficina de Olivia Pope porque está segura de que su marido no se ha suicidado y ha sido asesinado. Sólo puede ayudarles Molly, una joven que muere misteriosamente, justo antes de decir al equipo de Olivia Pope quién es el topo de la Casa Blanca, que intenta acabar con el gobierno del presidente Grant (reserva y neutralización de la información negativa).

Episodio 19: Siete cincuenta y dos (Seven fifty-two): Este capítulo vuelve al pasado para contarnos cómo Huck se convirtió en espía y asesino del gobierno (reserva). Incumplió la primera norma de renunciar a una vida familiar, y se casó y tuvo un hijo. Su compañero, Charlie, tenía órdenes de matarle pero le dejó marchar a cambio de que se convirtiera en un fantasma. Olivia le vio en el metro, como un vagabundo, y le dio una nueva vida. Al final del capítulo, descubrimos que Huck estaba en el 
suburbano porque todos los días laborables, su mujer y su hijo llegaban en el tren de las 7:52. Ellos no saben que sigue vivo porque Huck quiere protegerles.

Episodio 20: Una mujer despreciada (A woman scorned): Mellie Grant da un ultimátum a su marido: tiene 36 horas para pedirle perdón o dará una rueda de prensa diciendo que su marido le es infiel (límites temporales en la negociación). Cyrus Beene, asesor del presidente, le pide que oiga y atienda a sus peticiones. Sin embargo, Grant cree que la verdad sólo puede destruirles a los dos. Mellie sigue adelante y concede la entrevista al periodista James Novak, marido de Cyrus Beene, jefe del gabinete del presidente, para hacer daño por partida doble (publicación y puesta en escena).

Episodio 21: ¿Alguna pregunta? (Any questions?): Cyrus Beene da una rueda de prensa y dice que el presidente mantendrá sus asuntos familiares en privado porque el devenir de su matrimonio no afecta a la nación (reserva y puesta en escena). Nadie imagina que la amante es Olivia Pope. Mientras, Mellie Grant contrata a otro gestor de crisis, contrincante de Olivia, para que le ayude. El presidente decide dar una rueda de prensa y sólo dice "Mi matrimonio no es asunto vuestro" y pide el apoyo a la nación para presentarse a su segunda legislatura (neutralización de la información negativa). Olivia le ha recomendado que sea valiente, se presente a las elecciones y las gane legítimamente; por encima de la relación amorosa que mantienen.

Episodio 22: El nuevo sombrero blanco (White hat's back on): El presidente Grant convoca en una reunión a Olivia, su mujer, su portavoz y Hollis Doyle, los mismos que amañaron las máquinas de voto en la ciudad de Defiance. Ahora, debe recuperar la única prueba que queda de aquel amaño, que está en manos de David Rosen y del gobernador Reston (reserva). El presidente Grant recupera esa prueba dando una nueva oportunidad a Rosen y le nombra fiscal del distrito de Columbia en una multitudinaria rueda de prensa (puesta en escena). El episodio y la temporada acaban dejando entrever que los vídeos sexuales entre el presidente y Olivia han sido filtrados a la prensa y ella no puede salir de su casa, ante la multitud de periodistas que la esperan en la calle (filtración personal).

\section{Conclusiones}

En las líneas anteriores, hemos ahondado en las crisis planteadas, desarrolladas y resueltas por Olivia Pope y los trabajadores de su agencia, en los 29 capítulos emitidos, de la serie norteamericana Scandal. Cada uno de ellos está inspirado en crisis reales y supone una brillante exposición de cómo comunicar e informar. Queda demostrado que podrían ser ejemplo didáctico de información y comunicación en las aulas universitarias. Para el análisis se han empleado los manuales de Mauro Wolf (1987), Felicísimo Valbuena (1997) y Eva Aladro (1999). Sin embargo, el análisis de los episodios puede quedar abierto a muchas otras teorías, igualmente interesantes. 


\section{Bibliografía}

ALADRO, E. (1999). Teoría de la Información y la Comunicación efectiva. Madrid: Fragua.

MARTÍNEZ DE ALBÉNIZ, I. y MORENO DEL RÍO, C. (eds.) (2013). De Anatomía de Grey a The Wire. La realidad de la ficción televisiva. Madrid: Los Libros de la Catarata.

PADILLA, G. (2010). Las series de televisión sobre médicos (1990-2010): tres enfoques: comunicación interpersonal, comunicación institucional, relaciones entre ética, moral y política. Madrid: Universidad Complutense de Madrid. Disponible en: http://eprints.ucm.es/11399/1/T32391.pdf Consultado el 6 de junio de 2013.

PADILLA, G. y REQUEIJO, P. (2010). "La sitcom o comedia de situación: orígenes, evolución y nuevas prácticas". En Fonseca: Journal of Communication, $\mathrm{n}^{\mathrm{0}} 1$. Disponible en: http://fjc.usal.es/index.php/sumario1/54-lasitcon Consultado el 12 de septiembre de 2013.

PADILLA, G. y REQUEIJO, P. (2011). "Las series de televisión como nuevo vehículo publicitario de la música". En Index.comunicación: Revista científica en el ámbito de la Comunicación Aplicada, $\mathrm{n}^{\mathrm{o}}$ 1. Disponible en: http://journals.sfu.ca/ indexcomunicacion/index.php/indexcomunicacion/article/view/17 Consultado el 12 de septiembre de 2013.

VV.AA. (1999). Salud, comunicación y sociedad. Bilbao: Fundación BBV.

VALBUENA, F. (1997). Teoría General de la Información. Madrid: Noesis.

WOLF, M. (1997). La investigación de la comunicación de masas, Crítica y perspectiva. Barcelona: Paidós.

\section{La autora}

Graciela Padilla Castillo es Profesora titular interina de la Facultad de Ciencias de la Información (Universidad Complutense de Madrid). Sus líneas de investigación abordan Teoría de la Información, Ficción televisiva, Ética audiovisual, Estudios de Género, Redes sociales y Redes profesionales, y Análisis Transaccional. Doctora en Ciencias de la Información, con Premio Extraordinario de Doctorado, ha completado su formación posdoctoral en la Universidad de California en Los Ángeles (UCLA). Es autora y coautora de más de sesenta capítulos de libro y artículos publicados en revistas científicas. Miembro del Instituto de Investigaciones Feministas (Universidad Complutense de Madrid), colabora en la coordinación del Máster universitario en Comunicación Política y Empresarial (Universidad Camilo José Cela). 
